\title{
Habitus, gênero de discurso e gênero de atividade: construtos para compreender o trabalho docente
}

\author{
Daniela Dias dos Anjos ${ }^{1}$ \\ Universidade São Francisco (Bragança Paulista, SP, Brasil)
}

Este texto tem por objetivo apresentar um diálogo entre os conceitos de habitus (Bourdieu), gênero de discurso (Bakhtin) e gênero de atividade (Clot), pensando em sua contribuição para a análise do trabalho docente. Os três conceitos versam sobre a tensão dialética entre a dinâmica social e a ação dos agentes/sujeitos/indivíduos. Bourdieu, Bakhtin e Clot dialogam com os autores dos seus respectivos campos do conhecimento e criticam a visão dicotômica dessa relação social/individual. Os autores apontam para um sujeito que age e se constitui a partir de uma história de práticas e de discursos socialmente produzidos. Neste texto indaga-se sobre as possíveis aproximações e as distinções conceituais que possam propiciar um refinamento conceitual e teórico e contribuir para a análise do trabalho docente, atividade profissional que se realiza em meio a uma história de práticas e dizeres já existentes, constituídos por aqueles que vivenciam/vivenciaram a profissão.

Palavras-chave: Trabalho docente, Habitus, Gênero de atividade, Gênero de discurso.

Habitus, speech genre and genre of activity: constructs for comprehending teachers' work

This text presents a dialog between the concepts of habitus (Bourdieu), speech genre (Bakhtin) and genre of activity (Clot) in order to contribute to the analysis of teachers' work. These three concepts address the dialectic tension between the social dynamics and the action of agents/subjects/individuals. Bourdieu, Bakhtin and Clot have held a dialog with the authors of their respective fields of knowledge and criticized the dichotomous vision of this social-individual relation. They highlight subjects who act and constitute themselves from a history of socially produced practices and speeches. We thus investigate possible conceptual approximations and distinctions that may favor a conceptual and theoretical refinement and contribute to the analysis of teachers' work: a professional activity that occurs amidst a history of practices and speeches that already exist and have been constituted by those who live(d) this profession.

Keywords: Teachers' work, Habitus, Genre of activity, Speech genre.

\section{Introdução}

$\mathrm{O}$ interesse por esses três conceitos emerge de estudo anterior sobre o início da carreira docente. Tais conceitos nos ajudaram a ampliar a compreensão da configuração das dificuldades vivenciadas pelas professoras iniciantes que participaram daquele estudo. As professoras entrevistadas, ao falarem sobre o início profissional, indicaram a existência de modos de fazer estabilizados nas escolas em que ingressaram. Relataram que havia uma série de práticas que elas não conheciam, modos de ação tidos como comuns, naturais daqueles que já faziam parte da instituição.

Há um processo de socialização que ocorre quando do ingresso na carreira. Nesse processo há novos aprendizados: modos de fazer, de dizer e de conceber que são oriundos da prática e não circunscritos apenas à formação inicial. Os profissionais vão desenvolvendo modos de agir que se repetem e que, muitas vezes, sequer se tem a consciência de que se está fazendo.

Este artigo tem por objetivo colocar em discussão três conceitos que ajudam a pensar na história das práticas que se institucionalizam em nossas escolas. Buscamos pensar na inter-relação entre eles e em sua contribuição para a análise do trabalho docente. Para tanto, apresentamos, em um primeiro momento, cada um dos conceitos, para então pensar nas relações entre eles, a partir de dizeres de professoras que participaram de um trabalho de análise da atividade docente, no contexto de uma pesquisa de doutorado.

1 Professora do Programa de Pós-Graduação em Educação da Universidade São Francisco (USF). 


\section{Habitus, gênero de discurso e gênero de atividade}

Estes três conceitos foram elaborados a partir de diferentes campos do conhecimento: sociologia, linguística e psicologia, respectivamente, por três pensadores e pesquisadores cujas ideias começaram a repercutir mais amplamente na segunda metade do século XX: Pierre Bourdieu (França, 1930-2002), sociólogo com uma vasta produção sobre diversos campos das ciências sociais. "Bourdieu fez avançar a sociologia ao se situar, como ele costumava dizer, no lugar geométrico entre Marx, Durkheim e Weber" (Pereira, 2007, p. 7); Michail Bakhtin (Rússia, 1895-1975), filósofo da linguagem, estudioso de literatura, inspirador de importantes estudos linguísticos; e Yves Clot (França, 1952-), psicólogo, responsável pela Equipe de Clínica da Atividade no Conservatoire National des Arts et Métiers (CNAM), em Paris, onde desenvolve pesquisas e análises sobre a atividade de trabalho. Bakhtin, Canguilhem, Tosquelles e Vygotsky são algumas das importantes referências na construção de seu pensamento e nos modos de atuação junto aos profissionais nos meios de trabalho.

Os três autores estão preocupados com os pressupostos da ação e/ou dizer individual e com a forma como eles se relacionam com o contexto social. Criticam o objetivismo e o subjetivismo. Recusam a ideia de que a ação individual seja determinada diretamente pela estrutura social, bem como de que aquela seja completamente independente desta.

Sabemos que a proposta de compreensão e diálogo entre esses conceitos coloca em cena muitos debates em torno de cada um dos conceitos e dos autores, tanto no interior dos campos de conhecimento aos quais eles estão ligados como na intersecção entre os campos. Não se trata aqui de esgotar o debate, mas de contribuir para a problematização dos conceitos, buscando explorar analiticamente sua fecundidade e seu alcance.

\section{Habitus}

Ao falar sobre a origem do conceito de habitus, Bourdieu (2010a) afirma que sua elaboração permite "romper com o paradigma estruturalista sem cair na velha filosofia do sujeito ou da consciência" (p. 61).

O conceito de habitus perpassa toda a obra de Bourdieu. Em Esboço para uma teoria da prática, o autor defende um modo de conhecimento praxiológico em oposição à perspectiva fenomenológica e a objetivista. Segundo ele, o conhecimento praxiológico tem por objeto não só o sistema de relações objetivas, mas também as relações dialéticas entre essas estruturas e as disposições estruturadas nas quais elas se atualizam e que tendem a se reproduzir. Propunha uma pesquisa do modus operandi, a construção de uma teoria da prática, ou ainda, uma teoria dos modos de produção das práticas.

As estruturas constitutivas de um tipo particular de meio (as condições materiais de existência características de uma condição de classe), que podem ser apreendidas empiricamente sob a forma de regularidades associadas a um meio socialmente estruturado, produzem habitus, sistemas de disposições duráveis, estruturas estruturadas predispostas a funcionar como estruturas estruturantes, isto é, como princípio gerador e estruturador das práticas e das representações que podem ser objetivamente "reguladas" e "regulares" sem ser o produto da obediência a regras, objetivamente adaptadas a seu fim sem supor a intenção consciente dos fins e o domínio expresso das operações necessárias para atingilos e coletivamente orquestradas, sem ser o produto da ação organizadora de um regente (Bourdieu, 1983, pp. 60-61). 
O habitus é o que "explica" que o sujeito aja de uma dada maneira e não de outra. Define coisas a fazer ou a não fazer, dizer ou não dizer, "modos adequados de agir . . . socialmente aceitos, que fazem sentido para o indivíduo e para o seu grupo de uma forma tal que são percebidos como naturais, inquestionáveis" (Lugli, 2007, p. 28). Aquilo que se faz sem se "calcular de um modo completamente consciente, sem avaliar as consequências imediatas, basicamente porque consideramos que é o 'certo"' (Lugli, 2007, p. 28). "O habitus é a mediação universalizante que faz com que as práticas sem razão explícita e sem intenção significante de um agente singular sejam, no entanto, 'sensatas', 'razoáveis' e objetivamente orquestradas" (Bourdieu, 1983, p. 73).

Impulsos para realizar atividades de um modo determinado, para conceber comportamentos como aceitáveis ou não, para conduzir a vida de um determinado modo. "São disposições, porque se referem a um nível pré-consciente, por assim dizer; e são incorporadas porque nos estruturam socialmente como pessoas" (Lugli, 2007, p. 28).

História incorporada, que se inscreve na mente, no corpo, nos gestos. Para o autor, a história existe em seu "estado objetivado, quer dizer, a história que se acumulou ao longo tempo nas coisas, máquinas, edifícios, monumentos, livros, teorias, costumes, direito etc., e a história em seu estado incorporado, que se tornou habitus" (Bourdieu \& Passeron, 2010, p. 82).Nessa perspectiva, o corpo, o modo de andar, de se vestir, os costumes, os gestos, o modo de falar são fruto do habitus.

Um sinal de aprovação aqui, um franzir de sobrancelhas ante a uma gargalhada rude ali são pequenos sinais cotidianos que corrigem o comportamento na maior parte da infância e adolescência, e que passam desapercebidos para aqueles que participam do processo, assim como a maior parte dos processos de socialização (Lugli, 2007, p. 31).

Bourdieu (2010) fala da identificação de papéis, da manutenção de posições e da participação dos sujeitos na construção do habitus, o que acaba por contribuir para a manutenção de uma ordem social dada, ainda que sem querer ou saber.

A subordinação do conjunto das práticas a uma mesma intenção objectiva, espécie de orquestração sem maestro, só se realiza mediante a concordância que se instaura, como por fora e para além dos agentes, entre o que estes são e o que fazem, entre a sua "vocação" subjectiva (aquilo para que se sentem "feitos") e a sua "missão" objectiva (aquilo que deles se espera), entre o que a história fez deles e o que ela lhes pede para fazer, concordância essa que pode exprimir-se no sentimento de estar bem "no seu lugar", de fazer o que se tem que fazer, e de o fazer com gosto - no sentido objectivo e subjectivo - ou na convicção resignada de não poder fazer outra coisa, o que também é uma maneira, menos feliz certamente, de se sentir destinado para o que se faz (pp. 86-87).

Mesmo as condições de trabalho mais alienantes e repugnantes podem ser "assumidas e suportadas por um trabalhador que as percebe, as aprecia, as ordena, as acomoda e se lhes acomoda em função de toda a sua história própria e até mesmo da sua descendência" (p. 87). Bourdieu (2010) fala ainda de um acordo "tácito estabelecido entre as condições de trabalho mais desumanas e os homens que estão preparados para as aceitar por terem condições de existência desumanas", em função de um processo de "inculcamento do mundo social que pode predispor a aceitação de tais condições" (pp. 96-97).

Ao mesmo tempo em que Bourdieu coloca tamanha força nas condições de existência, na determinação dos destinos sociais dos sujeitos, que acabam por contribuir para a lógica social vigente, afirma ser necessário abandonar todas as teorias que defendem que a prática seja uma reação mecânica, determinada pelas condições antecedentes. Mais de uma vez ele ressalta o 
aspecto dialético do conceito de habitus, a partir do qual defende que a ação não é mero produto das relações sociais, assim como não é fruto apenas das intenções individuais do sujeito.

Segundo Wacquant (2007), uma das incompreensões do conceito de habitus reside no fato de ser visto como um "mecanismo autossuficiente para a geração da ação" (p. 69). Segundo o autor, o habitus "opera como uma mola que necessita de um gatilho externo e não pode, portanto ser considerado isoladamente dos mundos sociais particulares, ou 'campos', no interior dos quais evolui" (p. 69).

O habitus teria também um caráter de individuação "porque cada pessoa, ao ter uma trajetória e uma localização únicas no mundo, internaliza uma combinação incomparável de esquemas" (Wacquant, 2007, p. 68). Aí residiria um caráter que poderíamos chamar de criativo, do ponto de vista do sujeito em relação ao que se espera dele. A ação seria "uma espécie de luta entre a história objetivada e a história incorporada” (Bourdieu, 2010, p. 103).

As mudanças de geração, as novas condições de existências produzem novos habitus, novas definições do que é possível/impossível, impensável/provável, razoável/escandaloso.

Bourdieu (1983) fala ainda da existência de um estilo pessoal, que seria uma marca particular daqueles que participam de um mesmo habitus. Mas considera que ela não passe de "um desvio, ele próprio regulado e às vezes mesmo codificado, em relação ao estilo próprio a uma época ou a uma classe, se bem que ele remete ao estilo comum não somente pela conformidade . . . mas também pela diferença que constitui todo 'modo'” (p. 81).

Dentre os temas de estudo privilegiados por Bourdieu encontra-se a Educação. Segundo Nogueira e Nogueira (2002), ele "teve o mérito de formular . . uma resposta original, abrangente e bem fundamentada, teórica e empiricamente, para o problema das desigualdades escolares. Essa resposta tornou-se um marco na história ... do pensamento e da prática educacional” (p. 16).

Uma das obras de grande repercussão no Brasil foi A Reprodução. Elementos para uma Teoria do Sistema de Ensino (Bourdieu \& Passeron, 1970/2010).

\begin{abstract}
Na obra, analisa-se a ação pedagógica como ação de violência simbólica, istoé, de inculcação de significações e de legitimação dessas mesmas distinções. Elas desentranham das situações de ensino as formas pelas quais tal violência é exercida pelos agentes pedagógicos devidamente autorizados na instituição. Assim é que, para dar conta das especificidades do sistema educacional, são examinadas as diversas relações que se concretizam na instituição escolar entre o capital cultural dos indivíduos e os modos de viver a comunicação pedagógica, os discursos dos professores e as formas de compreensão dos alunos, o papel dos exames e os modos de selecionar os que podem ascender socialmente pela educação (Catani, 2007, p. 18).
\end{abstract}

Catani (2007) aponta que a interpretação dessa obra no Brasil centrou-se na dicotomia "reprodução versus transformação", deixando de lado as análises de Bourdieu que visavam explicitar os modos de funcionamento da escola e sua lógica de reprodução, para que então se pudesse intervir nela.

Ao gerar cuidadosa análise das formas pelas quais a escola concretiza, no cotidiano, sua função reprodutora das relações de dominação vigentes na sociedade, Bourdieu não pretendia decretar a impossibilidade das transformações. Ele sustentou, em inúmeras oportunidades, que muitas das críticas que lhe foram feitas por causa de interpretações como essa deixaram de levar em conta a aposta feita por ele na possibilidade de se intervir a partir do conhecimento das leis próprias da lógica da reprodução (p. 18).

Dentre os elementos que contribuiriam para a reprodução, estaria a ação docente, que, sendo um habitus em exercício, acabaria por contribuir para reproduzir as relações sociais. Em estudo 
sobre o Juízo Professoral, no qual Bourdieu analisou as avaliações emitidas por professores, na década de 1960, ele afirma que as notas e os comentários avaliativos se relacionavam diretamente à posição social dos alunos. Os professores acabavam por reforçar as diferenças sociais, valorizando qualidades e características que estavam fora do sistema escolar, tais como postura, entonação, aparência. No entanto, os professores realizavam essas ações, sem terem a consciência do que estavam fazendo.

Eles só fazem bem o que tem a fazer (objetivamente) porque acreditam fazer uma coisa diferente do que fazem; porque fazem uma coisa diferente do que acreditam fazer; porque eles acreditam no que eles acreditam fazer. Mistificadores mistificados, eles são as primeiras vítimas das operações que efetuam. É porque acreditam operar uma classificação propriamente escolar . . . que o sistema pode operar uma verdadeira reviravolta do sentido de suas práticas, conseguindo que eles façam aquilo que nem "por todo dinheiro do mundo" fariam. (Bourdieu \& Saint-Martain, 2007, pp. 198-199).

Autores afirmam que o habitus professoral se manifesta nos momentos em que surgem situações imprevistas, nas quais é necessário agir rapidamente (Lugli, 2007; Silva, 2005). Nesses momentos, o que daria o suporte para a ação seria o habitus, que se relaciona com a história de vida daquele sujeito. Lugli (2007) considera que "as raízes dessas ações, que parecem instintivas, podem ser localizadas no repertório de práticas que todo docente acumula desde suas vivências como aluno" (p. 29).

O ingresso na profissão implicaria na aprendizagem do habitus professoral. Incorporação de normas, modos de fazer, conhecimentos, valores "que, ao integrarem-se na sua personalidade, fazem que o indivíduo tenha um sentimento de pertença a um grupo" (Ferreirinho, 2005, p. 15). É necessária uma inserção do professor no meio profissional, compreendendo suas demandas, esperados para que possa "responder às solicitações da maneira esperada", podendo assim ser "visto como um bom profissional" (Ferreirinho, 2005, p. 16). No entanto, segundo Ferreirinho (2005), não se trataria apenas de uma "adaptação do professor à escola, mas também da escola ao professor, numa dinâmica contínua de acomodação e enfrentamento de ambas as partes" (p. 15-16).

A noção de habitus nos leva a pensar que, ainda que os iniciantes não mostrem uma adesão imediata a certas práticas encontradas, em muitos casos, mesmo involuntariamente, acabam incorporando certos modos de agir estabilizados no campo profissional. Isso em decorrência das próprias condições de realização do trabalho, dentre as quais está o fato de só serem vistos como bons profissionais na medida em que aprendem as "regras do jogo".

Haveria uma busca de adequação em relação às ações e à organização da instituição local. Segundo Lugli (2007), essa busca de adequação "praticamente impede o questionamento das condições específicas nas quais determinadas práticas sociais se realizam” (p. 32).

Este conceito nos leva a pensar nos modos pelos quais as condições objetivas de existência afetam, circunscrevem e, por vezes, limitam a ação dos indivíduos. Levanta questões sobre o papel dos sujeitos na produção e na transformação dessas condições de existência.

\section{Gênero de discurso}

De acordo com Bakhtin (2003), "o dizer" se realiza no gênero de discurso, a partir de formas típicas de enunciados produzidos na história humana, em diferentes domínios de atividade. "Os enunciados e seus tipos, isto é, os gêneros discursivos, são correias de transmissão entre a história da sociedade e a história da linguagem" (Bakhtin, 2003, p. 268). Segundo o autor, 
Todos os diversos campos da atividade humana estão ligados ao uso da linguagem. Compreende-se perfeitamente que o caráter e as formas desse uso sejam tão multiformes quanto os campos da atividade humana. O emprego da língua efetua-se em forma de enunciados (orais e escritos) concretos e únicos, proferidos pelos integrantes desse ou daquele campo da atividade humana. Esses enunciados refletem as condições específicas e as finalidades de cada referido campo não só por seu conteúdo (temático) e pelo estilo da linguagem, ou seja, pela seleção dos recursos lexicais, fraseológicos e gramaticais da língua, mas, acima de tudo, por sua construção composicional. Todos esses três elementos - o conteúdo temático, o estilo, a construção composicional - estão indissoluvelmente ligados no todo do enunciado e são igualmente determinados pela especificidade de um determinado campo da comunicação. Evidentemente, cada enunciado particular é individual, mas cada campo de utilização da língua elabora seus tipos relativamente estáveis de enunciados, os quais denominamos gêneros do discurso [ênfase do original] (p. 261-262).

Há uma riqueza e uma diversidade de gêneros porque as possibilidades da atividade humana são inesgotáveis. Os gêneros correspondem às condições específicas de um dado campo de atividade.

Várias vezes no texto Os gêneros do discurso, de Bakhtin, publicado em 2003, encontramos a fórmula: o enunciado é um elo na corrente de outros enunciados. Para ele, o dizer não é um ato isolado da atividade individual, mas se inscreve na história humana. A possibilidade de falar, de escolher as palavras, se dá a partir de coisas já enunciadas antes pelo sujeito, pelos outros. "Todo falante é por si mesmo um respondente em maior ou menor grau: porque ele não é o primeiro falante, o primeiro a ter violado o eterno silêncio do universo" (Bakhtin, 2003, p. 272).

A vontade discursiva do falante se realiza pela escolha de um gênero de discurso. Escolha que é "determinada pela especificidade de um dado campo da comunicação discursiva, por considerações semântico-objetais (temáticas), pela situação concreta da comunicação discursiva, pela composição pessoal dos seus participantes, etc.” (p. 282).

Bakhtin (2003) afirma que os gêneros são empregados "de forma segura e habilidosa" (p. 282), mesmo que não se conheça sua existência.

Esses gêneros de discurso nos são dados quase da mesma forma que nos é dada a língua materna, a qual dominamos livremente até começarmos o estudo teórico da gramática. A língua materna . . . não chega ao nosso conhecimento a partir de dicionários e gramáticas mas de enunciações concretas que nós mesmos ouvimos e nós mesmos reproduzimos na comunicação discursiva viva com as pessoas que nos rodeiam. ... Aprender a falar significa aprender a construir enunciados (porque falamos por enunciados e não por orações isoladas e, evidentemente, não por palavras isoladas). . . . Nós aprendemos a moldar nosso discurso em formas de gênero e, quando ouvimos o discurso alheio, já adivinhamos seu gênero pelas primeiras palavras . . . uma determinada construção composicional, prevemos o fim, isto é, desde o início temos a sensação do conjunto do discurso que em seguida apenas se diferencia no processo da fala. Se os gêneros do discurso não existissem e nós não os dominássemos, se tivéssemos que criá-los pela primeira vez no processo do discurso, de construir livremente e pela primeira vez cada enunciado, a comunicação discursiva seria impossível (pp. 282-283).

Portanto, os gêneros permitem que a comunicação discursiva se realize. Eles dão sentido aos enunciados individuais. Sentidos que podem variar de acordo com o contexto em que o enunciado é produzido. Para conseguir utilizá-los livremente, é necessário dominá-los.

Quanto mais dominamos os gêneros tanto mais livremente os empregamos, tanto mais plena e nitidamente descobrimos neles a nossa individualidade (onde isso é possível e necessário), refletimos 
de modo mais flexível e sutil a situação singular da comunicação; em suma, realizamos de modo mais acabado o nosso livre projeto de discurso (Bakhtin, 2003, p. 285).

Bakhtin (2003) critica a fórmula de Saussure que contrapõe o "enunciado (la parole) como ato puramente individual ao sistema da língua como fenômeno puramente social e obrigatório para o indivíduo" (p. 285), vendo no enunciado apenas uma combinação individual de "formas puramente da língua (léxicas e gramaticais)" (p. 286). Para Bakhtin (2003), "um enunciado singular, a despeito de toda a sua individualidade e do caráter criativo, de forma alguma pode ser considerado uma combinação absolutamente livre de formas da língua”. Portanto, tem um "significado normativo para os sujeitos" (pp. 285-286).

Na história humana, em diferentes épocas há a produção de enunciados tipos, com os quais o enunciado individual dialoga. "A experiência discursiva individual de qualquer pessoa se forma e se desenvolve em uma interação constante e contínua com os enunciados individuais dos outros" (Bakhtin, 2003, p. 294). Trata-se de um processo de apropriação das palavras alheias.

O próprio objeto de discurso de um enunciado de um dado falante é permeado pelos discursos dos outros sobre ele, sobre o que já foi dito sobre ele. "O falante não é um Adão, e por isso o próprio objeto do seu discurso se torna inevitavelmente um palco de encontro com opiniões de interlocutores imediatos ... ou com pontos de vista, visões de mundo, correntes, teorias, etc." (Bakhtin, 2003, p. 300). No entanto, o enunciado relaciona-se também aos elos subsequentes da comunicação. "Desde o início o falante aguarda a resposta deles, espera uma ativa compreensão responsiva. É como se todo o enunciado se construísse ao encontro dessa resposta" (Bakhtin, 2003, p. 301).

A composição e o estilo do enunciado dependem de seu destinatário. "Cada gênero do discurso em cada campo de comunicação discursiva tem a sua concepção típica de destinatário que o determina como gênero" (Bakhtin, 2003, p. 301).

Ao falar, sempre levo em conta o fundo aperceptível da percepção do meu discurso pelo destinatário: até que ponto ele está a par da situação, dispõe de conhecimentos especiais de um dado campo cultural da comunicação; levo em conta as suas concepções e convicções, os seus preconceitos (do meu ponto de vista), as suas simpatias e antipatias - tudo isso irá determinar a ativa compreensão responsiva do meu enunciado por ele. Essa consideração irá determinar também a escolha do gênero do enunciado e a escolha dos procedimentos composicionais e, por último, dos meios linguísticos, isto é, o estilo do enunciado (Bakhtin, 2003, p. 302).

É necessário levar em conta ainda as relações entre o sujeito e o destinatário, a posição social, as imagens. Faïta (2005, p. 165), retomando a proposição de F. François, diz que "as estruturas e combinações de palavras, não são . . . o ponto de chegada da atividade de linguagem, mas pelo contrário, são a retomada do processo em que se entrelaçam certamente as vozes, mas também, e sobretudo, os papéis".

Para Bakhtin (2003), o estilo tem uma dimensão individual e coletiva, "tanto os estilos individuais como os da língua satisfazem aos gêneros do discurso” (p. 302). Coletiva, pois nossa fala se realiza por meio de gêneros do discurso típicos, relativamente estabilizados. Estes gêneros se concretizam por meio de enunciados concretos, proferidos pelos indivíduos singulares, possibilitando a estilização individual.

O enunciado nunca é apenas um reflexo, uma expressão de algo já existente fora dele, dado e acabado. Ele sempre cria algo que não existia antes dele, absolutamente novo e singular ... Contudo, alguma coisa criada é sempre criada a partir de algo dado (a linguagem, o fenômeno observado da 
realidade, um sentimento vivenciado, o próprio sujeito falante, o acabado em sua visão de mundo, etc.) (Bakhtin, 2003, p. 326).

É na dinâmica entre gêneros e estilos, no curso da história de utilização da língua através dos enunciados concretos proferidos pelos sujeitos falantes, que ocorre a possibilidade de variação linguística.

Essas elaborações de Bakhtin nos levam a pensar na configuração de um gênero de discurso docente em, pelo menos, duas direções: o discurso no trabalho, na situação de aula; e o discurso sobre o trabalho.

A análise da atividade docente evidencia alguns tipos de enunciados: no modo de se referir aos alunos, de instruir, explicar conteúdos, chamar atenção.

Outra questão são os enunciados sobre o trabalho, dirigidos aos colegas de profissão, aos pais, ou numa situação de análise da atividade. Nesses casos, também podemos encontrar formas típicas, que variam em acordo com o destinatário - não se fala sobre o trabalho pedagógico com os pais do mesmo modo que se fala com os colegas.

a escola é um lugar em que atuamos em diferentes esferas de atividades. Cada esfera de atividade nos exige uma forma específica de atuar com a linguagem. Dessa forma, temos uma esfera de atividade que é a aula, outra que é a reunião de pais e mestres, a reunião dos professores, o encontro dos alunos no recreio etc., cada uma dessas esferas exigindo uma forma específica de uso da linguagem (Brandão, 2004. p. 99).

Em ambos os casos - a linguagem no trabalho e a linguagem sobre o trabalho - há um encadeamento do que é dito no curso de uma história que ultrapassa o sujeito falante.

Segundo Faïta (2004), os gêneros de discurso podem ser considerados como instrumento de ação. Podem ser apropriados pelos interlocutores a serviço da ação no contexto da troca verbal.

\section{Gênero de atividade}

O conceito de gênero de atividade é elaborado a partir do conceito de gêneros de discurso de Bakhtin. Além de modos de dizer que se estabilizam nos diferentes campos da atividade humana, haveria também modos de fazer relativamente estabilizados (Clot, 2006a, 2010).

Clot (2006a) concebe o regime de utilização de técnicas em um meio profissional como um gênero de técnicas, que faz a ligação entre a tarefa prescrita e os subentendidos de um meio. Haveria, então, não só um gênero de discurso em funcionamento, que define enunciados aceitáveis ou deslocados, mas também gestos, maneiras de fazer aceitáveis ou não.

De acordo com Clot, a mesma crítica feita por Bakhtin (2003) à dicotomia língua prescrita/ fala real no campo da linguística pode ser aplicada às ciências do trabalho, com a dicotomia trabalho prescrito/trabalho real. Clot (2010) propõe uma renovação na tradição francófona na análise do trabalho.

Em nosso entender, não existe, de um lado . . . a organização do trabalho e, do outro, a atividade do sujeito. Existe entre a organização do trabalho e o próprio sujeito, um trabalho de reorganização da tarefa pelos coletivos profissionais ... Entre o prescrito e o real, há um terceiro termo decisivo que designamos como gênero profissional (p. 119). 
Para agir, os trabalhadores se impõem formas prescritas que são recursos para a ação. Retomando a fórmula de Bakhtin sobre a linguagem, Clot (2010) afirma que, "se fosse necessário criar, a cada vez na ação, cada uma de nossas atividades, o trabalho seria impossível. O gênero assenta, portanto, em um princípio de economia de ação" (p. 121).

O gênero é, de algum modo, a parte subentendida da atividade, o que os trabalhadores de dado meio conhecem e observam, esperam e reconhecem, apreciam ou temem; o que lhes é comum, reunindoos sob condições reais de vida; o que sabem que devem fazer, graças à uma comunidade de avaliações pressupostas, sem que seja necessário reespecificar a tarefa cada vez que ela se apresenta. É como uma "senha" conhecida somente por aqueles que pertencem a um mesmo horizonte social e profissional (pp. 121-122).

Preocupações e soluções partilhadas para enfrentar os dilemas do real da atividade. Uma maneira coletiva de digerir a prescrição oficial, de revitalizá-la. História e memória profissional, produzida por aqueles que estão hoje no ofício, mas também por aqueles que já fizeram parte dele em algum momento. Maneiras de se comportar, de dirigir a palavra, de realizar uma atividade. $\mathrm{O}$ repertório dos atos aceitáveis ou deslocados. Um estoque de práticas que pode servir de recurso para a ação (Clot, 2006a).

$\mathrm{Na}$ maior parte dos casos, são regras não escritas, sequer enunciadas, mas conhecidas por aqueles que fazem parte do mesmo horizonte profissional. Unem aqueles que participam de uma mesma situação como coautores que conhecem, compreendem e avaliam uma situação de uma mesma maneira.

$\mathrm{Na}$ arquitetura conceitual proposta por Clot $(2007)^{2}$ para análise do ofício, o gênero seria a dimensão transpessoal. Além dela, há a dimensão impessoal, que se refere às tarefas prescritas, e as dimensões interpessoal e pessoal, através das quais o ofício se realiza.

O ofício no sentido que compreendemos é ao mesmo tempo pessoal, interpessoal, transpessoal e impessoal. Pessoal e interpessoal em cada situação singular, primeiro como atividade real sempre exposta ao inesperado. Sem destinatário, a atividade perde seu sentido . . . Ele é em seguida transpessoal, pois atravessado por uma história coletiva que ultrapassou diversas situações e dispôs sujeitos de gerações diferentes a responderem a ela. São os esperados genéricos da atividade ... O trabalho coletivo de reorganização da tarefa assegura ou não sua 'manutenção'. . . Enfim, o ofício é impessoal, desta vez sob o ângulo da tarefa ou da função definida. Esta última é, na arquitetura da atividade de um trabalhador, o que é necessariamente mais descontextualizado. Mas ela é justamente o que sustenta o ofício para além de cada situação particular, cristalizada na organização ou instituição ... O ofício passa também pela tarefa prescrita. É ela que o retém o codificando, longe de atividade efetiva, como um modelo esfriado a descongelar por cada um e por todos, face o real, com a ajuda dos esperados da história comum (Clot, 2007, p. 86).

Fazendo uso desses pressupostos para analisar a atividade docente, Saujat (2004) defende a existência de um gênero de atividade docente:

Sustentaremos, de fato, que o ofício docente, assim como a palavra-enunciado em Bakhtin, tem três aspetos simultâneos. O ofício neutro da prescrição, o ofício de outrem, e o ofício de si mesmo, ao mesmo tempo. Entre o docente e a sua tarefa interpõem-se intercalares sociais (intercalaires sociaux) ... que chamaremos de "gêneros de atividades professorais". Assim como os "gêneros de discurso"

2 Todos os textos em francês foram traduzidos pela própria autora. 
de Bakhtin, esses gêneros, através dos quais o trabalho docente se realiza, constituem menos normas profissionais acabadas do que sistemas abertos de modos de fazer e pensar compartilhados que se apresentam ao professor como "recursos que lhe evitam vaguear sozinho . . . diante da extensão infinita das besteiras possíveis" (p. 68).

Quando um noviço entra em um meio profissional, ele se vê diante de vários subentendidos, de regras implícitas que podem definir suas ações como deslocadas. Segundo Saujat (2004), a análise da atividade de professores iniciantes revela a existência dessas formas estáveis, maneiras de agir reconhecidas e validadas pelo meio profissional.

Os gêneros, relativamente estabilizados, são uma maneira de saber se comportar no mundo, de saber como agir. É o interior da atividade, sua coluna vertebral, o que sustenta, o que liga os órgãos entre si.

No entanto, os gêneros são sempre inacabados. Sua vitalidade depende das variações estilísticas.

O estilo individual é, antes de mais nada, a transformação dos gêneros na história real das atividades no momento de agir em função das circunstâncias .... Mas inversamente, o não domínio do gênero e de suas variantes impede a elaboração do estilo. Servir-se com certa liberdade dos gêneros implica sua refinada apropriação (Clot, 2010, p. 126).

A estilização é o desenvolvimento da tradição, da história coletiva. Não inventamos as coisas fora do gênero, fora da história. A estilização é fazer, de outro modo, o que foi feito até o momento presente. Mas ela só é possível, se o gênero não se encontra necrosado, fechado a novas estilizações. Um gênero necrosado não permite uma apropriação pessoal.

Quando alguém chega a um novo meio de trabalho, há um processo de apropriação do gênero profissional que acontece nas relações com a tarefa prescrita, os subentendidos do coletivo de trabalho (o gênero) e os inesperados do real. De acordo com Clot e Roger (2005), a estilização começa a partir do momento que o sujeito domina o gênero em funcionamento, tornando-o próprio.

Portanto, a apropriação do gênero não significa fixar certo encadeamento de ações obrigatórias, mas beneficiar-se de um conteúdo que permite a cada um "fazer uso" dos esquemas operatórios e simbólicos já construídos, para constituir outros (Clot \& Roger, 2005). Trata-se de uma repetição sem repetição. Não somente uma adesão às práticas estocadas, mas um diálogo com elas.

O estilo é também a distância que um profissional interpõe entre sua ação e sua própria história. No contato com o real, a experiência individual do sujeito tem um papel importante. Seus esquemas operatórios, perceptivos, corporais, emocionais ou ainda relacionais e subjetivos compõem uma espécie de gênero interior que dialoga com a dimensão impessoal (prescrição) e com a dimensão transpessoal da atividade (o gênero profissional). É na intersecção dessas três dimensões que a estilização pode se realizar. "O estilo é essa liberação dos pressupostos genéricos da ação pela qual se realiza um duplo enriquecimento desses mesmos pressupostos: o enriquecimento dos contatos sociais consigo mesmo e o das relações pessoais estabelecidas com os outros" (Clot, 2010, p. 130).

Poderíamos nos perguntar como essa liberação pode se produzir, tendo em conta os contextos de vida e trabalho dos sujeitos. As condições objetivas poderiam impedir o processo de estilização?

A invenção estilística supõe ainda a participação do sujeito em vários gêneros ao mesmo tempo. Essa possibilidade de agir num dado gênero, a partir da percepção e dos recursos de outro gênero, é essencial para a criação estilística (Clot, 2006a).

Poder ver um gênero com os olhos de outro gênero, poder agir num gênero com os recursos de outro gênero é com certeza o recurso essencial da criação estilística ... O repertório genérico de um sujeito pode ultrapassar o repertório do gênero da situação em que ele trabalha (pp. 188-199). 
Segundo o autor, o emperramento da dinâmica das relações entre estilos e gêneros está na origem das situações patogênicas de trabalho. "A história de um meio de trabalho continua se - e somente se - ela é aprovisionada pelas contribuições estilísticas, acrescidas ao patrimônio no decorrer de uma percolação a recomeçar constantemente na amálgama das gerações" (Clot, 2010, p. 127).

Nessa perspectiva, o gênero tem um ponto decisivo para a mobilização psicológica do trabalho, pois é um meio através do qual o sujeito pode ter o sentimento de pertencimento a um coletivo de trabalho.

De acordo com Roger (2007),

a atrofia atual da dimensão transpessoal e a carência de recursos genéricos permitindo fazer frente às obrigações do trabalho a realizar pode se traduzir como uma desregulagem das dimensões interpessoais do ofício. Os conflitos profissionais podem então se transformar em pessoais intrapsíquicos sem soluções. Do mesmo modo, quando, por falta do coletivo, a dimensão pessoal do ofício e sua dimensão impessoal se confundem, o trabalho torna-se difícil, custoso, por vezes insuportável (p. 31).

Essas considerações nos fazem pensar na história coletiva da profissão docente. Estudos no campo da educação indicam um gênero de atividade "fragilizado", "desregulado", "atrofiado" (Freitas, 2013; Lapo \& Bueno, 2003; Leite \& Souza, 2007; Oliveira, 2004; Sampaio \& Marin, 2004;). Indicam, portanto, a não liberação dos pressupostos genéricos na direção de uma estilização profissional. Os professores têm tido cada vez menos possibilidade de atuar como autores de seu próprio trabalho.

\section{Habitus, gênero de discurso, gênero de atividade}

Nesta seção apresentaremos uma reflexão sobre as possíveis aproximações e as distinções entre os conceitos, buscando um refinamento conceitual e teórico a partir da análise de uma situação concreta.

No contexto de uma pesquisa de doutorado, quatro professoras assistiam e analisavam conjuntamente vídeos de suas aulas. Dentre os diversos temas destacados por elas, encontra-se a percepção que tiveram, ao se verem trabalhando, de que fazem uso excessivo da palavra nas aulas e deixam pouco espaço para os alunos tentarem resolver as tarefas sozinhos. Uma das professoras participantes da pesquisa comenta, após assistir ao vídeo da aula de uma colega:

M: às vezes eu percebo que eu chego até a matar a atividade sabe, com essa coisa da fala mesmo, dessa necessidade que todos prestem atenção ao mesmo tempo numa mesma orientação, acreditando que, se aquela orientação for bem escutadinha, eles vão fazer... E aí assim, eu vi um fragmento ali, não sei se isso é muito frequente. Porque tanto na minha filmagem quanto na sua filmagem tem esses momentos, de uma faaaala, e aí de um foco BEEM centrado na gente, e depois as crianças, eles com eles, mas eles com eles sempre com a nossa voz de fundo...

O falar em excesso parece ser uma das "marcas" que caracterizam a atividade docente. As quatro professoras se reconhecem na atitude de falar em excesso e indicam que se trata de algo que faz parte do coletivo e não está circunscrito apenas a elas. Poderíamos afirmar que esse modo de dizer, que se caracteriza por uma fala longa, explicando a atividade a ser realizada, repetindo frases que já são conhecidas pelos alunos, caracteriza o gênero de discurso em aula. Segundo Faïta (2004), "enunciados produzidos por diferentes locutores, em circunstâncias diferentes, num domínio de atividade idêntica, como o ensino" apresentam "uma soma de traços recorrentes, indicando que 
pertencem a um mesmo tipo" (p. 156). Confrontados a dilemas parecidos - conseguir que os alunos compreendam e realizem as atividades corretamente -, professores fazem uso da estratégia da explicação exaustiva.

O diálogo das professoras a partir do tema da fala excessiva levou-as a uma reflexão sobre o modo como ministram suas aulas e sua postura diante dos alunos. Trouxeram para a discussão os embates da história da educação entre concepções diferenciadas sobre a aula e a postura do professor - aula centrada no professor, aula centrada no aluno, etc. Apontaram que, apesar de terem passado por uma formação que incentivava uma prática que desse mais voz às crianças, ainda fica forte nelas uma postura mais centralizadora:

I: a gente ainda é acostumado, em qualquer lugar que a gente vá se formar, tem alguém lá na frente falando. Então a gente ainda é acostumado de um estar falaaando, sempre, falando, e é ele que sabe, e aí a gente também é conduzido sempre a isso, nesse processo a fazer isso. Então até a nossa cabeça ainda é acostumada a isso, então, como que eu, Isnary, quando eu vou lá reproduzir isso consigo entender esse processo e soltar disso? Então às vezes eu tento fazer isso... mas ainda é difícil desamarrar cem por cento.

M: Porque, na verdade, eu acho que tem um pouco, sim, que é da personalidade, tem um jogo de poder que é alimentado ali na relação com os meninos que nos tranquiliza de certa maneira, você tem ali o controle da coisa quando você está à frente do grupo, encaminhando as atividades. Isso tranquiliza a gente. É o modelo de escola, uai... A gente, quando escolheu ser professora, escolheu ser alguém que faz isso. Eu quero fazer isso aí, ficar falando, escrever na lousa.

Retomando a argumentação de Bourdieu sobre o habitus, para interpretar essa situação, somos levados a pensar em práticas que parecem ter mais força e legitimidade que outras, que se mostram enraizadas na história da profissão, como, por exemplo, o uso excessivo da palavra sinalizado pelas professoras. Nesse sentido, no momento de agir, o professor tem como fonte as disposições incorporadas que atuam, independentemente da vontade dos sujeitos. Bourdieu (1996) nos fala do sentido do jogo "que faz com que se faça o que é preciso fazer no momento próprio, sem ter havido necessidade de tematizar o que havia de fazer, e menos ainda a regra que permite gerar a conduta adequada" (p. 23).

Vemos que, ainda que as professoras sinalizem um desejo de fazer diferente, se veem repetindo práticas historicamente constituídas. A oportunidade de se verem em ação, possibilitou essa percepção. No entanto, na maior parte dos casos, esse processo de reflexão não ocorre.

Se pensarmos a situação apresentada a partir do conceito de gênero de atividade de Clot, que, por sua vez, incorpora o conceito de gênero de discurso, temos que o que é realizado pelas professoras, apesar de ter relação com o gênero estabilizado, é sempre, em alguma medida, uma criação. Segundo Clot (2006a), "a ação pode fazer surgir diante de si possibilidades descobertas no curso da atividade e de que até esse momento mal se suspeitava. Aquilo que se realiza deixa vestígios que o gênero recusa, mantém, retrabalha e capitaliza mediante sucessivos refinamentos" (p. 104).

De acordo com Clot (2006b), no momento da realização da atividade há um questionamento do estabilizado do gênero, que pode revitalizá-lo. Retomando a contribuição de Leontiev, Clot (2006b) afirma que, na busca de um objetivo, uma ação pode se deparar com resultados inesperados, que podem tornar-se fonte de novas mobilizações psíquicas, reconfigurando o objetivo inicial. "A atividade é, portanto, construtora de novos motivos que o sujeito descobre depois da experiência ... nascidos não a partir dele mesmo, mas do real de sua atividade que, em parte, lhe escapa" (p. 233).

Uma questão apontada pelos três autores e também, de certo modo, ressaltada pelas professoras participantes da pesquisa é a questão do estilo individual. Como, diante de um 
conjunto de práticas institucionalizadas, esperados genéricos, configura-se uma criação individual, uma invenção estilística?

I: essa direção [da atividade], não conseguir distribuir as atividades e depois conversar. Conseguir mudar essa minha postura. Enquanto a M. falava, eu falei: mas será que não é uma marca? Minha enquanto professora?

O habitus, apesar de também reconhecer a existência de um estilo pessoal, que teria relação com o modo particular de incorporação da história, coloca bastante força nas condições materiais de existência, que muitas vezes dificulta, se não impede, a produção de novos possíveis. Impede, por exemplo, que os professores vislumbrem outras possibilidades de ação. Ou, ainda que as vislumbrem, não conseguem colocá-las em prática, tamanha a força das disposições incorporadas.

Já os conceitos de gênero de discurso e de gênero de atividade admitem a possibilidade de produção no novo de modo mais dinâmico. Bakhtin (2003) e Clot (2010) apontam que a estilização ocorre apenas na medida em que o gênero é apropriado. $O$ gênero, tornado próprio, possibilita a estilização e esta, por sua vez, revitaliza o gênero. É nesse contexto que ocorre, por exemplo, a variação linguística.

Consideramos que a ideia trazida com o conceito de habitus acerca da força das disposições incorporadas é importante para compreender a dificuldade ou a lentidão dos processos de mudança em educação.

$\mathrm{O}$ ato de ensinar condensa modos de fazer e de dizer que se inscrevem numa história de práticas que ultrapassa o sujeito em situação. Consideramos que os conceitos de gênero do discurso, gênero de atividade e habitus podem contribuir para a compreensão da atividade do professor, atividade que se realiza em meio a uma história de práticas e dizeres já existentes constituídos tanto por aqueles que vivenciam/vivenciaram a profissão como pela produção dos discursos sobre a educação.

\section{Referências}

Bakthin, M. (2003). Estética da criação verbal. São Paulo: Martins Fontes.

Bakhtin, M. (2004). Marxismo e filosofia da linguagem. São Paulo: Hucitec.

Bourdieu, P. (1983). Esboço de uma teoria da prática: precedido de três estudos de etnologia cabila. São Paulo: Ática.

Bourdieu, P. (1996). Razões práticas: sobre a teoria da ação. Campinas: Papirus.

Bourdieu, P. (2010). O poder simbólico. Rio de Janeiro: Bertrand Brasil.

Bourdieu, P., \& Passeron, J. (2010). A reprodução: elementos para uma teoria do sistema de ensino. Petrópolis: Vozes.

Bourdieu, P., \& Saint-Martin, M. (2007). As categorias do juízo professoral. In P. Bourdieu, Escritos de Educação (185216). Petrópolis: Vozes.

Brandão, H. H. N. (2004). Gêneros do discurso: unidade e diversidade. Polifonia, 7(8), 95-112.

Catani, D. B. (2007). A educação como ela é. Educação, 5, 16-25.

Clot, Y. (2006a). A função psicológica do trabalho. Petrópolis: Vozes.

Clot, Y. (2006b). Psicologia. In B. Braith (Org.), Bakhtin: conceitos-chave (pp. 219-240). São Paulo: Contexto.

Clot, Y. (2007). De l'analyse des pratiques au développement des métiers. Éducation et didactique, 1(1), 83-93.

Clot, Y. (2009). Clinic of activity: the dialogue as instrument. In A. Sannino, H. Daniels, \& K. Gutierrez (Eds.), Learning and expanding with activity theory (pp. 286-302). London: Sage.

Clot, Y. (2010). Trabalho e poder de agir. Belo Horizonte: FabreFactum.

Clot, Y., \& Roger, J. L. (2005). Généricité et stylisation: un exemple. Cahiers de l'IUFM de Rouen, 5, 13-26.

Faïta, D. (2003). Apports des sciences du travail à l'analyses des activités enseignantes. Skholé, hors-série, 1, 17-23.

Faïta, D. (2004). Mettre au travail les genres de discours. Polifonia, 7(8), 39-66. 
Faïta, D. (2005). A noção de "gênero discursivo" em Bakhtin: uma mudança de paradigma. In B. Brait (Org.), Bakhtin, dialogismo e construção do sentido (pp. 149-168). Campinas: Editora da Unicamp.

Ferreirinho, V. C. (2005). Práticas de socialização de professores iniciantes na carreira: quem é o iniciante? In 28a Reunião Anual da ANPEd. Caxambu, MG/Brasil: [s.n]. Recuperado de http://28reuniao.anped.org.br/textos/ gt14/gt141012int.doc

Freitas, L. C. (2013). Os reformadores empresariais da educação: da desmoralização do magistério à destruição do sistema público de educação. Educação Ė Sociedade, 33(119), 379-404.

Lapo, F. R., \& Bueno, B. O. (2003). Professores, desencanto com a profissão e abandono do magistério. Cadernos de Pesquisa (118), 65-88. Recuperado de http://www.scielo.br/scielo.php?script=sci_arttext\&pid=S0100. $15742003000100004 \& \operatorname{lng}=\mathrm{pt \& nrm}=$ iso

Leite, M. P., \& Souza, A. N. (2007). Condições de trabalho e suas repercussões na saúde de professores da educação básica no Brasil - Estado da Arte e Resenhas. Relatório de Pesquisa, FUNDACENTRO, MTE, 2007.

Lugli, R. S. G. (2007). A construção social do indivíduo. Educação, 5, 26-35.

Nogueira, C. M. M., \& Nogueira, M. A. (2002). A sociologia da educação de Pierre Bourdieu: limites e contribuições. Educação e Sociedade, 23(78) 15-35. Recuperado de http://www.scielo.br/scielo.php?script=sci_ arttext\&pid $=$ S0101-73302002000200003\&lng $=$ en\&nrm $=$ iso

Oliveira, D. A. (2004). A reestruturação do trabalho docente: precarização e flexibilização. Educação e Sociedade, 25(89), 1127-1144. Recuperado de http://www.scielo.br/scielo.php?script=sci_arttext\&pid=S0101. $73302004000400003 \& \operatorname{lng}=\mathrm{pt} \& \mathrm{nrm}=$ iso

Pereira, G. R. M. (2007). A improvável trajetória de um sociólogo enervante. Educação, 5, 6-15.

Roger, J. L. (2007). Refaire son métier: essais de clinique de l'activité. Toulouse: Erés.

Sampaio, M. M. F., \& Marin, A. J. (2004). Precarização do trabalho docente e seus efeitos sobre as práticas curriculares. Educação e Sociedade, 25(89), 1203-1225. Recuperado de http://www.scielo.br/scielo.php?script=sci_ arttext\&pid $=$ S0101-73302004000400007\&lng=pt\&nrm $=$ iso

Saujat, F. (2004). Spécificités de l'activité d'enseignants débutants et genres de l'activité professorale. Polifonia, 7(8), $67-93$.

Silva, M. (2005). O habitus professoral: o objeto dos estudos sobre o ato de ensinar na sala de aula. Revista Brasileira de Educação, 29, 152-163.

Wacquant, L. (2007). Esclarecer o habitus. Educação Ë Linguagem, 10, 63-71. Recuperado de

\section{Endereço para correspondência}

danjos04@yahoo.com.br
Recebido em: 30/07/2014

Revisado em: 14/07/2015

Aprovado em: 06/10/2015 